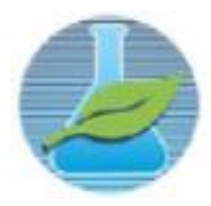

Vol. 03 N. 01 (2017) 007-009
JCEC/REQ ${ }^{2}$

Journal

ISSN: 2446-9416

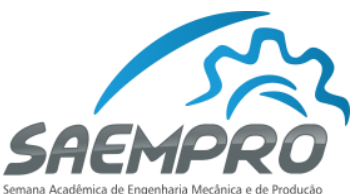

"EU, A INDÚSTRIA E O MUNDO"

08 a 11 de novembro de 2016 no campus Viçosa da UFV

Departamento de Engenharia de Produção e Mecânica - DEP

Universidade Federal de Viçosa - UFV

\title{
DIMENSIONAMENTO DO SISTEMA DE FREIOS DE UM VEICULO FORA DE ESTRADA
}

\author{
Raphael Neves Freitas Vidal \\ Universidade Federal de Viçosa, Departamento de Engenharia de Produção e Mecânica \\ Avenida Ph Rolfs, centro, campus universitário - 36570000 - Viçosa - Minas Gerais \\ raphael.vidal@ufv.br
}

\section{INTRODUÇÃ̃O}

Um sistema de freios tem como função manter o veículo imóvel ou pará-lo com a menor distância possível de forma segura, mantendo a dirigibilidade e a estabilidade.

Analisando o subsistema de freios do veículo anterior, verificou-se o desafio de melhorar o conforto do piloto. Desta forma, teve-se como meta reduzir o esforço necessário para o acionamento dos freios mantendo a robustez do carro anterior, tendo em vista um orçamento de apenas mil reais para melhorias.

\section{METODOLOGIA}

O dimensionamento dinâmico da frenagem do protótipo iniciou-se seguindo o procedimento: a desaceleração linear $\left(D_{x}\right)$ foi obtida pela relação entre o coeficiente de adesão da interação pneu/solo $(\mu)$ e a aceleração da gravidade $(g)$, como apresentado na Equação (1):

$D_{x}=\mu g$

Para determinar o valor do coeficiente de adesão, foi realizado um teste prático com o veículo 2015. O protótipo foi puxado até sair do repouso com as quatro rodas travadas, obtendo a força necessária por meio de um sistema de aquisição. Essa força representa a força de atrito estático quando o protótipo está na iminência do movimento e através dela foi calculado o coeficiente de adesão pneu solo $(\mu)$ igual a 0,72 .

Utilizando a notação proposta por (Gillespie, 1992), desconsiderando as forças aerodinâmicas por causa das baixas velocidades e considerando o ângulo de aclive igual a zero obtém-se as cargas dinâmicas no momento da frenagem nos eixos dianteiro $\left(W_{f}\right)$ e traseiro $\left(W_{r}\right)$, representadas pelas Equações (2) e (3) respectivamente.

$$
\begin{aligned}
& W_{f}=m g\left(\frac{c}{l}+\frac{D x}{g} \frac{h}{l}\right) \\
& W_{r}=m g\left(\frac{b}{l}-\frac{D x}{g} \frac{h}{l}\right)
\end{aligned}
$$

Na qual $m$ é massa total do veículo com piloto, $g$ a aceleração da gravidade, $c$ a distância do eixo traseiro ao centro de gravidade, $l$ a distância entre eixos, $D_{x}$ a desaceleração linear, $h$ a altura do centro de gravidade do veículo e $b$ a distância do eixo dianteiro ao centro de gravidade. 
Por definição, a força de frenagem na roda $\left(F_{x i}\right)$ é regida pela Equação (4):

$F_{x i}=W_{i} \mu$

Sendo $(i)$ o índice correspondente ao eixo. Considerando o raio efetivo do pneu, obtêm-se os torques nos eixos. Foi definido o diâmetro do disco de freio igual a $0,160 \mathrm{~m}$, pois era a maior dimensão disponível no espaço interno da roda, com isso determinou-se a força de frenagem que deve ser aplicada pelas pastilhas. O coeficiente de atrito disco/pastilha para os materiais utilizados é igual a 0,30 . Por meio dessa força e conhecendo o diâmetro do êmbolo das pinças $(0,032 \mathrm{~m})$, encontra-se a pressão hidráulica necessária para acionar o sistema. Assim, obteve-se as pressões para cada uma das pinças dos eixos dianteiro.

\section{DISCUSSÃO E RESULTADOS}

Com o intuito de atender as metas traçadas, adotou-se que o piloto deveria exercer uma força máxima de $445 \mathrm{~N}$, que representa a força máxima aplicada por uma mulher com um pé em uma posição de pilotagem esportiva (Limpert, 1999). Sendo o diâmetro do êmbolo do cilindro mestre igual a 0,02064 m, obteve-se a relação do pedal de 6:1 contra 5:1 do sistema antigo. Isso faz o piloto exercer menos força para parar o veículo, representando uma diminuição de $13,5 \% \mathrm{em}$ relação ao carro antigo. O curso do pedal aumentou de 0,032 para $0,036 \mathrm{~m}$.

Com base na opinião do piloto, em conceitos ergonômicos (Puhn, 1987) e realizando observações no veículo antigo chegou-se a um ângulo de posição do pedal de $30^{\circ}$. $\mathrm{O}$ material utilizado para confecção do pedal foi a liga de alumínio AISI 5052, pois esse material é $70 \%$ mais resistente ao escoamento que o Nylon, 66\% mais leve que o aço AISI 1020 e cerca de 35\% mais barato do que a liga de alumínio AISI 6061-T6.

O pedal foi desenhado no programa SolidWorks ${ }^{\circledR}$ e, em seguida feita uma análise estrutural. Devido à complexidade geométrica do elemento, foi aplicado o método por elementos finitos por meio do software ANSYS Workbench ${ }^{\circledR}$. A meta da análise era encontrar um fator de segurança mínimo de 1,5. Utilizou-se elementos de sólido tetraédrico de 4 nós. A simulação foi feita na condição de batente, para isso o pedal foi engastado na região onde ele é fixado no suporte e no cilindro mestre e aplicou-se uma força de $823 \mathrm{~N}$ (força máxima aplicada por um homem) na extremidade inferior. $\mathrm{O}$ componente foi submetido ao critério de von Mises. A tensão máxima obtida foi de $142 \mathrm{MPa}$, sendo inferior ao limite de escoamento do material de $214 \mathrm{MPa}$. O coeficiente de segurança obtido foi igual a 1,69, permitindo a conclusão da análise.

Fez-se necessário equipar o sistema de freios do protótipo com algum controle de pressão na linha. Uma válvula equalizadora com regulagem de pressão Wilwood ${ }^{\circledR}$ foi selecionada. A principal vantagem é que essa válvula permite usar quatro discos de freio intercambiáveis. No projeto a função da válvula é cortar a pressão para o eixo traseiro quando esse valor chega a 3,892 MPa.

Os componentes dos freios do veículo antigo foram analisados e alguns reutilizados para reduzir custos, pois ainda estavam em condições de uso. Para validar a teoria e comparar com o projeto passado, foram realizados testes dinâmicos para coletar dados de distância de frenagem na terra em função de determinadas velocidades. A Fig. 1 mostra que a distância de frenagem diminuiu cerca de 1 metro para velocidade máxima do veículo. 


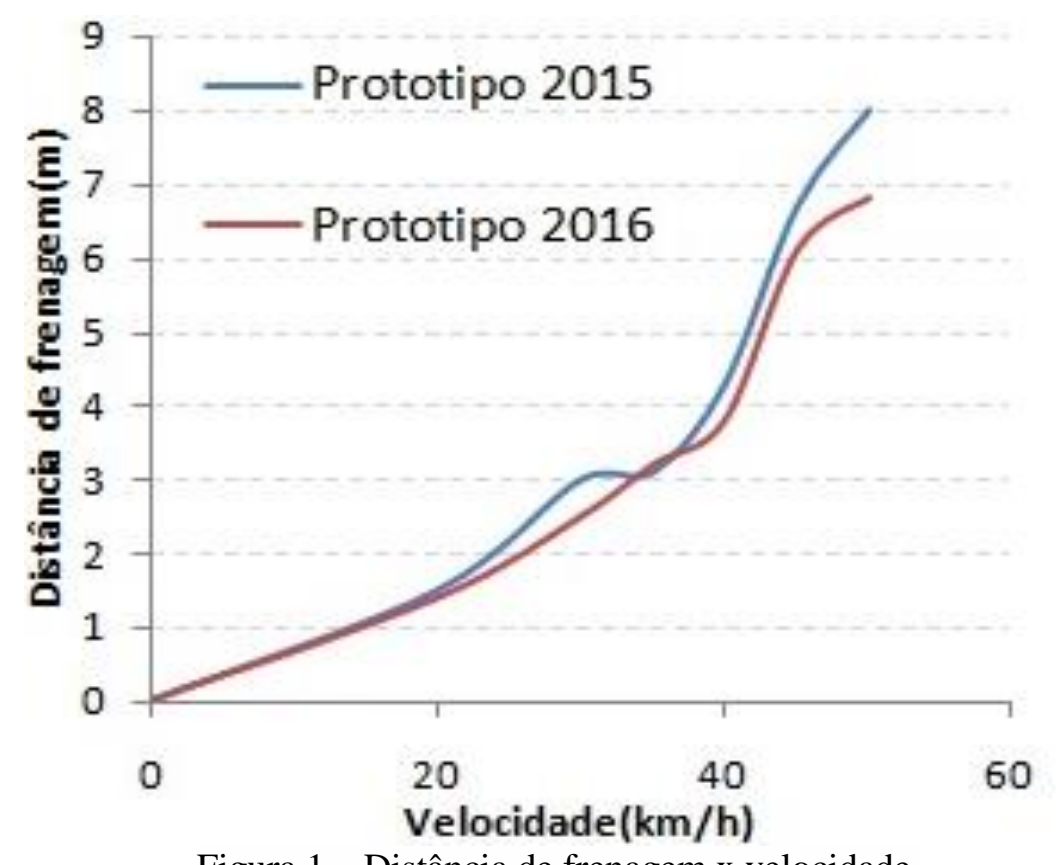

Figura 1 - Distância de frenagem x velocidade.

O custo de melhoria foi de $\mathrm{R} \$ 896,00$ e o de componentes reaproveitados $\mathrm{R} \$ 1400,00$. Com isso, o custo total do subsistema foi $\mathrm{R} \$ 2296,00$.

\section{CONCLUSÃO}

O sistema de freios do veículo UFVbaja 2016 melhorou o conforto do piloto ao diminuir a força de acionamento do freio, manteve a robustez, resistência e apresentou um custo inferior a $\mathrm{R} \$$ $1.000,00$, atingindo as metas.

\section{REFERÊNCIAS}

GILLESPIE, T.D. "Fundamentals of Vehicle Dynamics". Warrendale, PA, USA: SAE, 1992.

LIMPERT, R."Brake Design and Safety. 2 ed. Warrendale: Society of Automotive Engineers, 1999. PUHN, F. "Brake Handbook". 1 ed. New York, HpBooks, 1987. 